Article

\title{
Decoration of $\mathrm{ZnO}$ Nanorods with Coral Reefs like NiO Nanostructures by the Hydrothermal Growth Method and Their Luminescence Study
}

\author{
Mazhar Ali Abbasi ${ }^{1}{ }^{1}$, Zafar Hussain Ibupoto ${ }^{1}$, Mushtaque Hussain ${ }^{1}$, Galia Pozina ${ }^{2}$, Jun Lu ${ }^{2}$, \\ Lars Hultman ${ }^{2}$, Omer Nur ${ }^{1}$ and Magnus Willander ${ }^{1}$
}

1 Physical Electronics and Nanotechnology Division, Department of Science and Technology (ITN) Campus Norrköping, Linköping University, Norrköping SE-60174, Sweden;

E-Mails: zafar.hussain.ibupoto@liu.se (Z.H.I.); mushatque.hussain@liu.se (M.H.); omer.nour@liu.se (O.N.); magnus.willander@liu.se (M.W.)

2 Thin Film Physics Division, Department of Physics, Chemistry and Biology (IFM), Linköping University, Linköping SE-58183, Sweden; E-Mails: galia@ifm.liu.se (G.P.); junlu@ifm.liu.se (J.L.); larhu@ifm.liu.se (L.H.)

* Author to whom correspondence should be addressed; E-Mail: mazhar.ali.abbasi@liu.se; Tel.: +46-11-363-441; Fax: +46-11-363-270.

Received: 10 November 2013; in revised form: 8 January 2014 / Accepted: 9 January 2014 / Published: 15 January 2014

\begin{abstract}
Composite nanostructures of coral reefs like p-type $\mathrm{NiO} / \mathrm{n}$-type $\mathrm{ZnO}$ were synthesized on fluorine-doped tin oxide glass substrates by hydrothermal growth. Structural characterization was performed by field emission scanning electron microscopy, high-resolution transmission electron microscopy, and X-ray diffraction techniques. This investigation shows that the adopted synthesis leads to high crystalline quality nanostructures. The morphological study shows that the coral reefs like nanostructures are densely packed on the $\mathrm{ZnO}$ nanorods. Cathodoluminescence (CL) spectra for the synthesized composite nanostructures are dominated mainly by a broad interstitial defect related luminescence centered at $\sim 630 \mathrm{~nm}$. Spatially resolved CL images reveal that the luminescence of the decorated $\mathrm{ZnO}$ nanostructures is enhanced by the presence of the $\mathrm{NiO}$.
\end{abstract}

keywords: $\mathrm{ZnO}$ nanorods; $\mathrm{NiO}$ nanostructure; composite nanostructures; defect states; cathodoluminescent. 


\section{Introduction}

$\mathrm{ZnO}$ has been widely used for developing optoelectronics devices due to its versatile physical characteristics including wide direct bandgap of $3.37 \mathrm{eV}$, high exciton binding energy of $60 \mathrm{meV}$, and ability to transmit light [1]. $\mathrm{ZnO}$ nanomaterial is potentially used in different applications such as optoelectronics, sensors, actuators, optics, piezoelectric nanogenerator, and biomedical sciences [2,3]. Due to favorable properties exhibited by $\mathrm{ZnO}$ nanostructures, new trends can be followed in the application of heterojunction based nanomaterials with combined usability for the specific purpose such as UV-blue light emitting diodes (LEDs) [4] and UV photo detectors [5]. Thus, ZnO is a promising alternative material to $\mathrm{GaN}$, which has been extensively utilized in the LEDs operating in the UV-blue spectral window for more than two decades [4,6,7]. Despite several advantages of GaN, it is difficult to grow GaN nanowires for the development of nano-LEDs. Recently, a number of $\mathrm{p}-\mathrm{n}$ heterojunctions have been fabricated using n-type $\mathrm{ZnO}$ nanowires with p-type $\mathrm{GaN}$ or silicon [8-10].

Several growth techniques have been used for the fabrication of $\mathrm{ZnO}$ nanostructures [6-11]. Among them, the hydrothermal growth method is considered as cheap, simple, achievable at low temperature and environmentally friendly [11,12]. This method yields a material, which contains point defects contributing to defect-assisted emission under normal conditions [12]. Controlled morphology and highly oriented $\mathrm{ZnO}$ nanorods (NRs) can be achieved by using a seed layer of $\mathrm{ZnO}$ nanoparticles [10]. Since the fabrication of high-quality p-type $\mathrm{ZnO}$ is still a challenging task, an alternative $\mathrm{n}-\mathrm{ZnO} / \mathrm{p}$-based heterojunction has been explored [13]. Besides other p-type semiconducting materials, $\mathrm{NiO}$ attracts much interest because of some of its attractive properties such as wide direct bandgap of 3.6-4.0 eV at room temperature, high hole mobility and low lattice mismatch with $\mathrm{ZnO}$. Also, the synthesis of $\mathrm{NiO}$ is simple either in the form of thin films or nanostructures depending on the growth techniques. NiO nanostructures can be synthesized by the electrochemical method [14], sol gel technique [15], spray deposition method [16] and thermal evaporation [17]. The synthesis of $\mathrm{NiO}$ nanostructures can also be done by the simple, cheap, and low temperature aqueous chemical growth techniques [18,19]. By exploiting the properties of $\mathrm{NiO}$ nanostructures in combination with $\mathrm{ZnO}$ nanostructures quite a few p-n heterojunctions have been reported [20]. Few studies on the fabrication of p-type $\mathrm{NiO} / \mathrm{n}$-type $\mathrm{ZnO}$ heterojunctions with different techniques in which the interface properties have been investigated [21]. $\mathrm{NiO} / \mathrm{ZnO}$ composites have been studied extensively as $\mathrm{p}$-n diode, UV photo detectors [22,23] and LEDs [24,25]. In addition to this, the luminescence study of $\mathrm{ZnO}$ has been widely explored by coating different materials on $\mathrm{ZnO}$ nanostructures such as $\mathrm{MgO}$ [26,27] $\mathrm{Al}_{2} \mathrm{O}_{3}$ [28] and $\mathrm{SnO}_{2}$ [29,30], along with metals such as $\mathrm{Au}$ [31], $\mathrm{Ag}$ [32], and Pt [33] in order to enhance the near band edge (NBE) emission. However, fewer reports are available on the enhancement of the visible emission of $\mathrm{ZnO}$ by coating materials [34]. We believe that the composite nanostructures of $\mathrm{NiO} / \mathrm{ZnO}$ can pave the way for the fabrication of white LEDs due to the increased visible broad emission related to the defect states in the $\mathrm{ZnO}$ and defects at the interface of the heterojunction. The grown $\mathrm{NiO} / \mathrm{ZnO}$ composite nanostructures have revealed an enhanced red-shift in the visible emission compared to pure $\mathrm{NiO}$ and pure $\mathrm{ZnO}$ nanostructures, which might have resulted from a successful localized alloying of $\mathrm{NiO}$ on the $\mathrm{ZnO}$ nanorods that enhanced oxygen related interstitial defects.

Since $\mathrm{ZnO}$ nanostructures are of potential to many optoelectronic devices like LEDs, UV detectors etc. and unintentionally grown $\mathrm{NiO}$ is p-type, therefore it will be of interest to investigate the 
luminescence properties of $\mathrm{ZnO}$ nanorods decorated with $\mathrm{NiO}$ nanostructures. Thus, the presented composite nanostructures can be beneficial for further development of optoelectronic devices due to improved intensity of visible luminescence.

\section{Results and Discussion}

Figure 1 shows SEM images of the $\mathrm{p}-\mathrm{NiO} / \mathrm{n}-\mathrm{ZnO}$ composite nanostructures fabricated on FTO glass substrate together with a schematic diagram of the structure. As shown in Figure 1a, the ZnO NRs are well aligned and vertically oriented to the surface of the substrate and having a diameter of around 200-300 nm. Figure $1 \mathrm{~b}$ demonstrates that the $\mathrm{ZnO}$ NRs are uniformly covered with $\mathrm{NiO}$ forming flower-like arranged coral reefs with an average thickness of $\sim 50-80 \mathrm{~nm}$. The possible reaction mechanism for the preparation of the $\mathrm{ZnO}$ nanorods using zinc nitrate hexahydrate and hexamethylenetetramine as primary precursors is described below [35]:

$$
\begin{gathered}
\mathrm{C}_{6} \mathrm{H}_{12} \mathrm{~N}_{4}+6 \mathrm{H}_{2} \mathrm{O} \rightarrow 4 \mathrm{NH}_{3}+6 \mathrm{HCHO} \\
\mathrm{NH}_{3}+\mathrm{H}_{2} \mathrm{O} \rightarrow \mathrm{NH}_{4}^{+}+\mathrm{OH}^{-1} \\
\mathrm{Zn}^{2+}+2 \mathrm{OH}^{-1} \rightarrow \mathrm{Zn}(\mathrm{OH})_{2} \\
\mathrm{Zn}(\mathrm{OH})_{2} \rightarrow \mathrm{ZnO}+\mathrm{H}_{2} \mathrm{O}
\end{gathered}
$$

However, the decoration of $\mathrm{ZnO}$ nanorods with the $\mathrm{NiO}$ nanostructures was achieved by using nickel acetate and hexamethylenetetramine precursors in identical fashion as described above for $\mathrm{ZnO}$ nanorods:

$$
\begin{gathered}
\mathrm{C}_{6} \mathrm{H}_{12} \mathrm{~N}_{4}+6 \mathrm{H}_{2} \mathrm{O} \rightarrow 4 \mathrm{NH}_{3}+6 \mathrm{HCHO} \\
\mathrm{NH}_{3}+\mathrm{H}_{2} \mathrm{O} \rightarrow \mathrm{NH}_{4}^{+}+\mathrm{OH}^{-1} \\
\mathrm{Ni}^{2+}+2 \mathrm{OH}^{-1} \rightarrow \mathrm{Ni}(\mathrm{OH})_{2}
\end{gathered}
$$

Here, the nickel hydroxide nanostructures are accumulated on the surface of the $\mathrm{ZnO}$ nanorods. Further annealing of nanorods with nickel hydroxide nanostructures results in the formation of $\mathrm{NiO}$ nano-flakes due to the dehydration of nickel hydroxide as described below:

$$
\mathrm{Ni}(\mathrm{OH})_{2} \rightarrow \mathrm{NiO}+\mathrm{H}_{2} \mathrm{O}
$$

Figure 1c demonstrates a cross sectional SEM image of the $\mathrm{ZnO}$ nanorods covered with $\mathrm{NiO}$ nanostructures. Figure 1d illustrates the schematic diagram for the complete growth process of $\mathrm{ZnO}$ nanorods and decoration with $\mathrm{NiO}$ nanostructures on a FTO glass substrate. Figure 2a shows a high resolution transmission electron microscope (HRTEM) image together with the corresponding selected area electron diffraction (SAED) pattern of a single $\mathrm{ZnO}$ nanorod. It can be seen that the $\mathrm{ZnO} \mathrm{NR}$ exhibits single-crystal characteristics with a wurtzite crystal structure and is directed along the [001] direction. The HRTEM image of the $\mathrm{ZnO} \mathrm{NR}$ is shown in the inset of Figure 2a and the SAED analysis gave the lattice spacing as $0.26 \mathrm{~nm}$ for $\mathrm{ZnO} \mathrm{NRs}$ which corresponds to the (002)-lattice spacing of the hexagonal structure of single crystal $\mathrm{ZnO}$. The obtained HRTEM results thus confirm that a high crystalline quality of $\mathrm{ZnO}$ NRs has been achieved. Further, a HRTEM study was also 
carried out for the $\mathrm{NiO}$ nanostructures on the $\mathrm{ZnO}$ nanorods and the obtained results demonstrated that the $\mathrm{NiO}$ nanostructures consist of face centered cubic nanoparticles with a diameter of $\sim 20 \mathrm{~nm}$ as shown in Figure 2b.

Figure 1. (a) SEM image of pure $\mathrm{ZnO}$ nanorods; (b) SEM image of $\mathrm{ZnO}$ nanorods decorated with $\mathrm{NiO}$ nanostructures; (c) Cross sectional SEM image of the $\mathrm{ZnO}$ nanorods covered with $\mathrm{NiO}$ nanostructures; (d) Schematic diagram of composite $\mathrm{NiO} / \mathrm{ZnO}$ heterojunction formation.
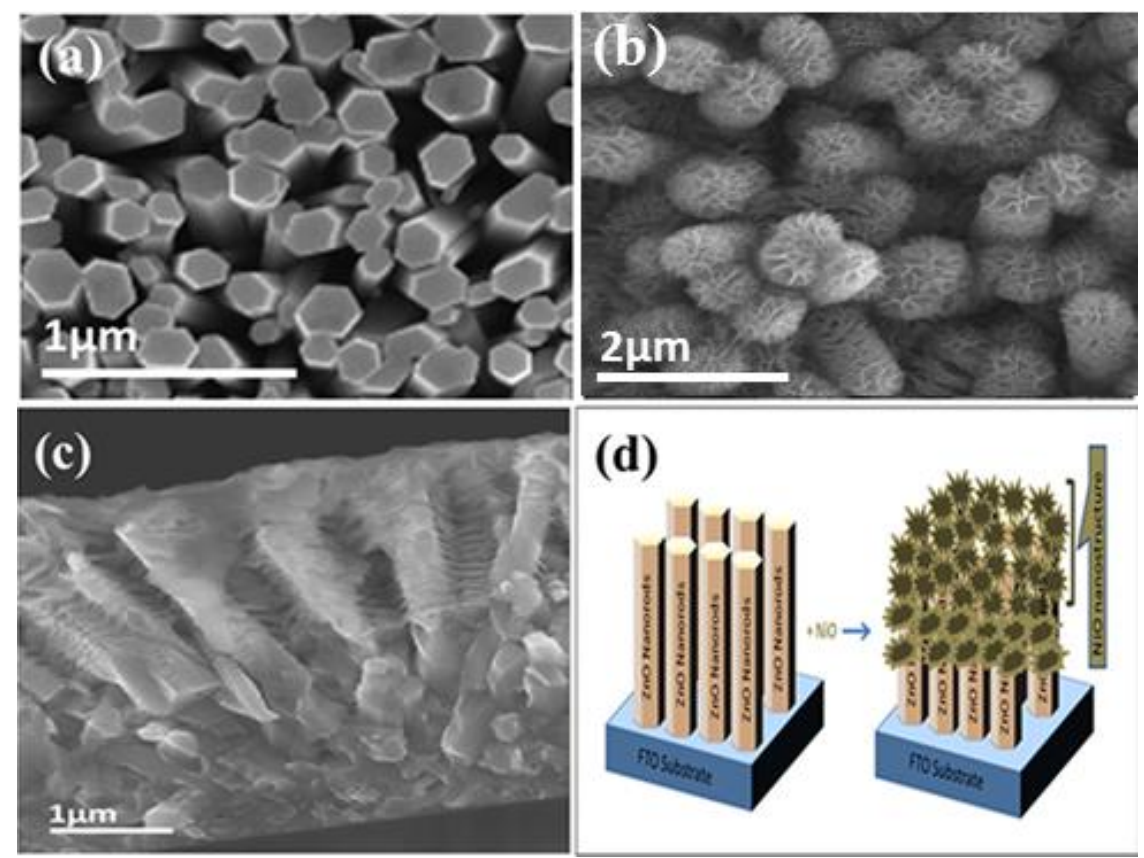

The XRD 2 $\theta-\omega$ spectrum of the $\mathrm{NiO} / \mathrm{ZnO}$ composite nanostructures is shown in Figure $2 \mathrm{c}$. Three of the observed diffraction peaks indicated by stars are indexed to reflections of the (111) and (200) planes of face centered cubic crystal structure of NiO (JCPDS No. 47-1049). Moreover, diffraction peaks of $\mathrm{ZnO} \mathrm{NRs}$ were also observed and these peaks can be assigned to the hexagonal wurtzite crystal phase of ZnO (JCPDS card No. 36-1451). As it can be seen from the XRD spectrum, a (002) peak is very intense, which demonstrates that the preferred growth direction of $\mathrm{ZnO}$ nanorods is along the c-axis. Other peaks are reflections from the FTO substrate. The combined results of the XRD and the HRTEM analysis show a rather high crystalline quality of both the $\mathrm{ZnO}$ and the $\mathrm{NiO}$ nanostructures.

Figure 3a shows a comparison of the room-temperature cathodoluminescence (CL) spectra of pure $\mathrm{NiO}$, pure $\mathrm{ZnO}$ and the $\mathrm{NiO} / \mathrm{ZnO}$ nanostructures grown separately on identical FTO glass substrates giving no contribution to the CL spectrum. The spectra are normalized and vertically shifted for the clarity. The pure $\mathrm{NiO}$ nanostructures showed a very weak broad emission with a maximum in the green region, which is in good agreement with reported work [36,37]. It is worth mentioning that the $\mathrm{CL}$ intensity acquired at the same conditions was weaker by a few orders of magnitude for $\mathrm{NiO}$ than for $\mathrm{ZnO}$ or the composite nanostructures. The CL spectra of $\mathrm{ZnO}$ NRs are dominated by two typical emissions centered at $383 \mathrm{~nm}$ and $610 \mathrm{~nm}$ correlated to the near band gap (NBG) and to point defects transitions, respectively [38,39]. Relative intensities for these two bands were similar for all the investigated $\mathrm{ZnO}$ NRs. In comparison to the pure $\mathrm{ZnO}$ NRs sample, the $\mathrm{CL}$ spectra of the $\mathrm{NiO} / \mathrm{ZnO}$ 
composite nanostructure demonstrate a significant enhancement of the defect emission at $650 \mathrm{~nm}$ compared to the $\mathrm{ZnO}$ NBG line at $383 \mathrm{~nm}$ (see Figure 3). Also, the composite nanostructures showed enhanced red shift of the peak position for the visible emission compared to pure $\mathrm{NiO}$ and $\mathrm{ZnO}$ nanostructures. It has been proven that the orange/red emission in $\mathrm{ZnO}$ is due to the oxygen interstitial which appears in the range of $620-690 \mathrm{~nm}$, however in the present case of $\mathrm{NiO} / \mathrm{ZnO}$ composite nanostructures, a small shift in the visible emission centered at $650 \mathrm{~nm}$ is observed due to enhanced oxygen related interstitial defects [40,41]. Normalized temperature dependent CL spectra of the composite $\mathrm{NiO} / \mathrm{ZnO}$ nanostructure are shown in Figure $3 \mathrm{~b}$. With increasing temperature from 5 to $295 \mathrm{~K}$, the NBG luminescence showed a typical red shift from $370 \mathrm{~nm}$ to $385 \mathrm{~nm}$ as illustrated in the inset of Figure $3 \mathrm{~b}$. We have also observed that the relative intensity between the visible and the NBG luminescence changes with temperature. The enhancement of the orange-red emission at $\sim 650 \mathrm{~nm}$ compared to the NBG line is clearly seen at $5 \mathrm{~K}$. This low energy luminescence tail can be explained by recombination between centers involving deep and shallow (localized states) level defects. With increasing temperature, shallow defects will be thermalized and thus do not contribute to the CL spectrum, which results in blue shift of the CL peak position $[41,42]$.

Figure 2. (a,b) TEM images with corresponding selected area electron diffraction (SAED) patterns of $\mathrm{ZnO} \mathrm{NR}$ and $\mathrm{NiO}$, respectively; (c) X-ray diffraction pattern for composite nanostructures of $\mathrm{NiO} / \mathrm{ZnO}$.

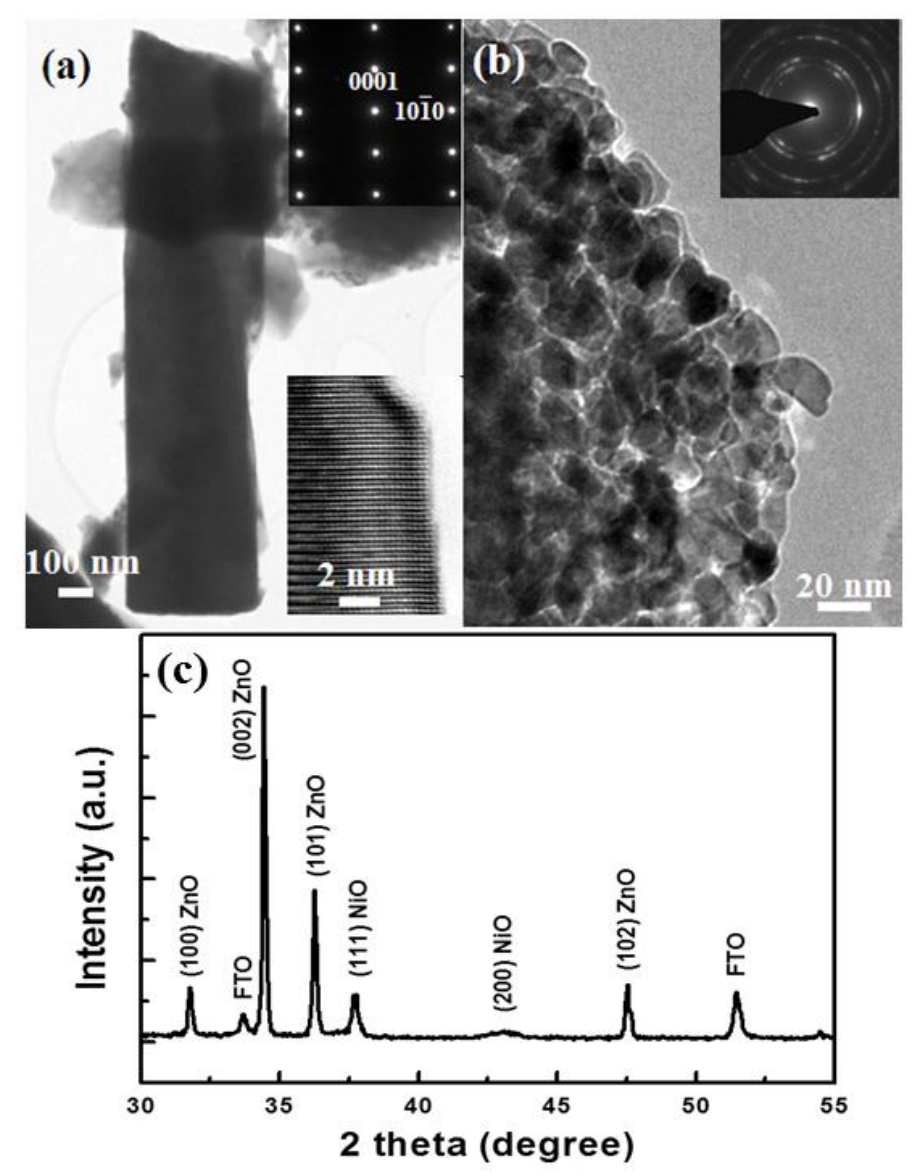


Figure 3. (a) Normalized CL spectra at room temperature for $\mathrm{NiO}, \mathrm{ZnO}$ and composite nanostructures; (b) Normalized CL spectra for $\mathrm{NiO} / \mathrm{ZnO}$ heterostructures shown at three different temperatures. Inset shows the effect of temperature on near band gap luminescence.

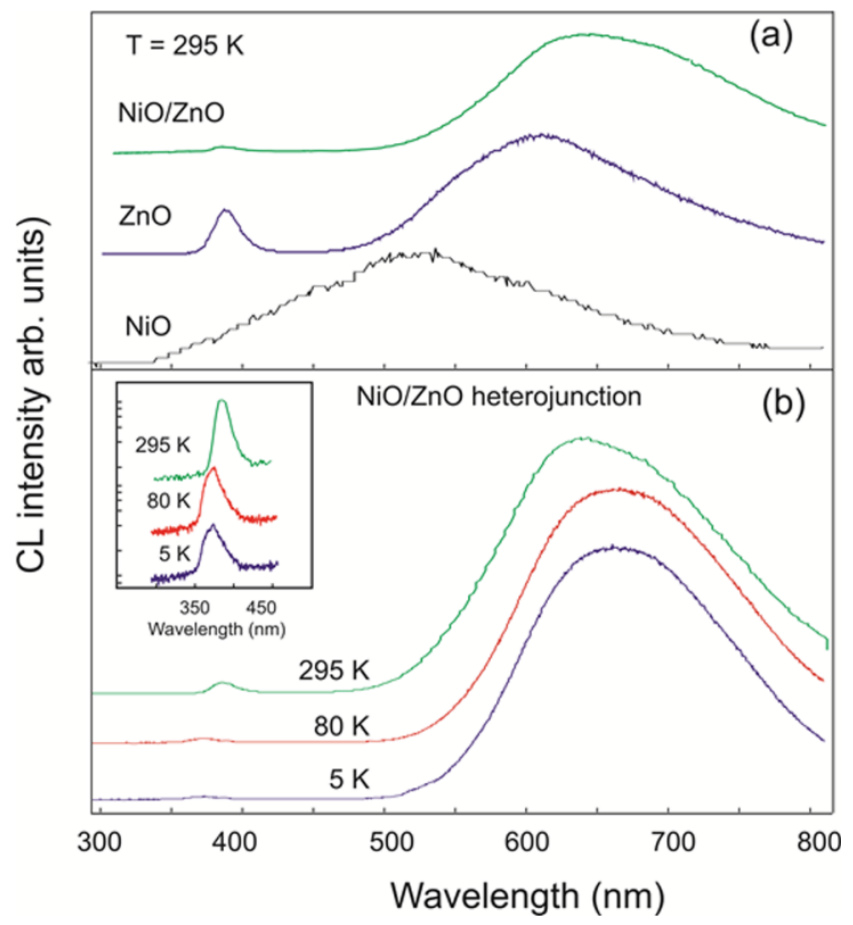

In addition to this, more investigations have been done for the cross sectional view of the composite nanostructures at $5 \mathrm{~K}$ and at $295 \mathrm{~K}$ as shown in Figure 4. An electron beam was located at five different spots starting from bare $\mathrm{ZnO}$ NRs located down close to the substrate indicated as spot 1 and moving gradually upwards the $\mathrm{ZnO} \mathrm{NR}$ part covered with coral reefs like $\mathrm{NiO}$ nanostructures indicated as spot 2 to spot 5, respectively. For each spot, we kept the acquisition parameters unchanged and only the electron beam position was moved. Figure $4 \mathrm{~b}$ illustrates the normalized CL spectra of these five spots. The relative intensity of the visible luminescence for the nanocomposite is much higher than the NBG emission as seen in Figure 4b. Figure 4c represents the comparative CL spectra of ZnO NRs and $\mathrm{NiO} / \mathrm{ZnO}$ nanostructures at $5 \mathrm{~K}$ denoted by spot 1 and spot 2, respectively. Since the experimental conditions were the same under measurements at these two points, one could note that the relative CL intensity is higher for the $\mathrm{NiO} / \mathrm{ZnO}$ heterojunction (i.e., for the $\mathrm{CL}$ spectrum taken at point 2 in Figure 4c). This CL behavior was confirmed for different places over the samples and also at low (5 K) and room temperature. Table 1 represents the quantitative ratio between the relative CL intensities at room temperature. Spot 1 is placed on the bare $\mathrm{ZnO}$ nanorods and then spot 2 to spot 5 are in the direction from $\mathrm{ZnO}$ to $\mathrm{NiO} / \mathrm{ZnO}$ heterojunction, such that the amount of $\mathrm{NiO}$ nanostructures is increasing gradually. At spot 1 , the quantitative ratio is only 2.5 but with a change in the beam position from spot 1 to spot 2 along a straight line without changing any other parameters, we observed a significant change in the quantitative ratio which is found to be double the quantitative ratio at spot 1. The ratio for spot 5 is 18 , which is almost eight times higher than that for spot 1, i.e., bare $\mathrm{ZnO}$. Since $\mathrm{NiO}$ contributes only negligibly to the CL intensity (as seen in Figure 3), we can conclude that enhanced defect related luminescence from the composite nanostructure is due to the influence of the 
p-type $\mathrm{NiO}$ on n-type $\mathrm{ZnO}$ and can be related to hole injection and simultaneous recombination of electrons and holes [43].

Figure 4. (a) Cross-sectional SEM image for $\mathrm{CL}$ of $\mathrm{NiO} / \mathrm{ZnO}$ composite nanostructures; (b) Normalized CL spectra for $\mathrm{NiO} / \mathrm{ZnO}$ heterostructures at five different spots; (c) CL spectra for $\mathrm{ZnO}$ and $\mathrm{NiO} / \mathrm{ZnO}$ heterojunction at $5 \mathrm{~K}$. Inset showing the cross sectional SEM view for these CL spectra.

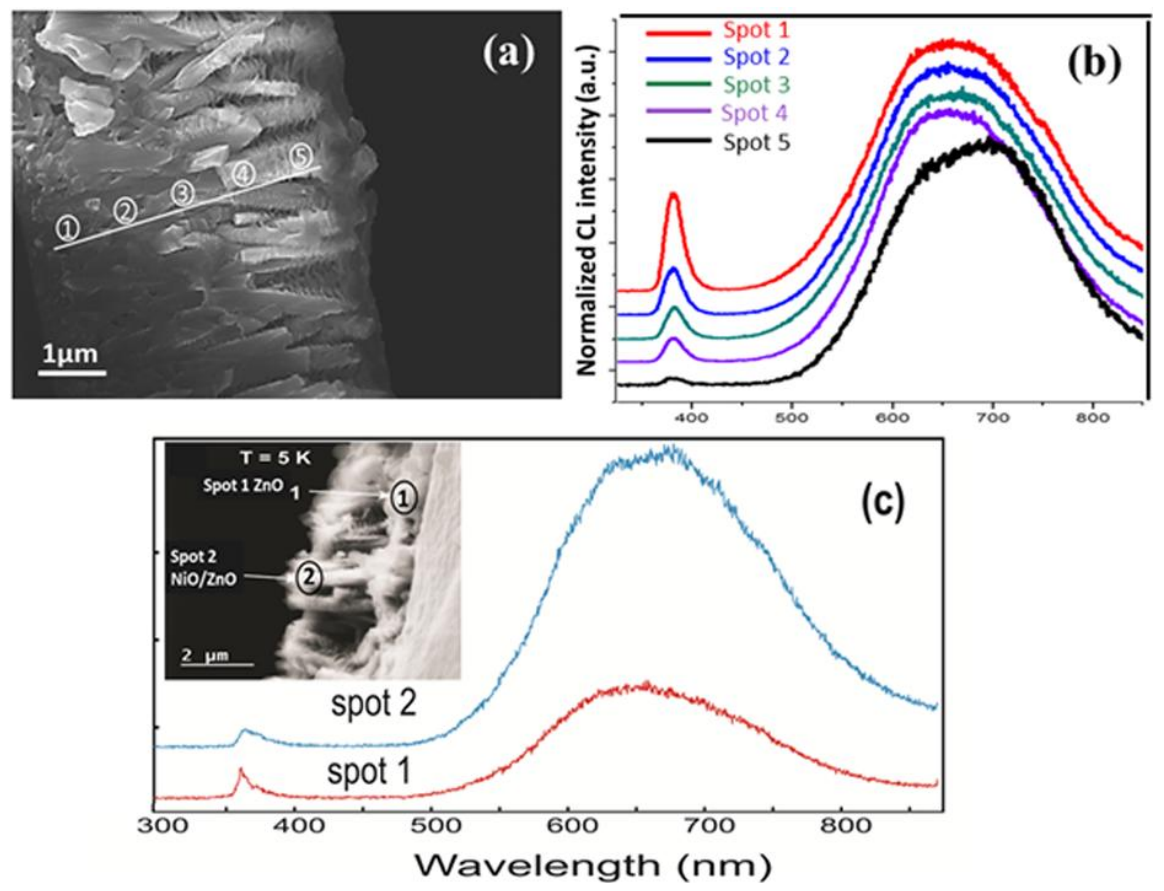

Table 1. Quantitative ratio of relative cathodoluminescence (CL) intensities at room temperature.

\begin{tabular}{cc}
\hline Spot & Quantitative ratio \\
\hline 1 & 2.5 \\
2 & 5 \\
3 & 6.8 \\
4 & 9.6 \\
5 & 18 \\
\hline
\end{tabular}

\section{Experimental Section}

Commercially available fluorine doped tin oxide (FTO) coated glass substrate was used for the synthesis of ZnO NRs by the hydrothermal growth method through two steps. In the first step, a seed solution of $\mathrm{ZnO}$ nanoparticles was spin coated on the substrate and subsequently annealed at $120{ }^{\circ} \mathrm{C}$. The seed solution of $\mathrm{ZnO}$ nanoparticles was prepared by dissolving $274 \mathrm{mg}$ of zinc acetate dihydrate in $125 \mathrm{~mL}$ of methanol and solution was left for constant stirring of $2 \mathrm{~h}$. At the same time $109 \mathrm{mg}$ of potassium hydroxide were dissolved in $65 \mathrm{~mL}$ of methanol separately and mixed with the zinc acetate dihydrate solution drop wise at the temperature of $60{ }^{\circ} \mathrm{C}$ [10]. In the second step, the annealed substrates were dipped vertically in the glass beaker containing equimolar $(0.075 \mathrm{M})$ solution of zinc nitrate hexahydrate and hexamethylenetetramine. After that the beaker was kept in preheated electric 
oven at $90{ }^{\circ} \mathrm{C}$ for duration of between 4 and $6 \mathrm{~h}$. Then, $\mathrm{NiO}$ nanostructures were fabricated on the $\mathrm{ZnO}$ nanorods also using the two-step hydrothermal growth method. In the third step, a seed solution of nickel acetate was spin coated on the $\mathrm{ZnO}$ nanorods and then nanorods were dipped in equimolar solution of nickel acetate and hexamethylenetetramine at $90{ }^{\circ} \mathrm{C}$ in the preheated electric oven for $4 \mathrm{~h}$. Finally, the sample of $\mathrm{NiO}$ nanostructures grown on the $\mathrm{ZnO} \mathrm{NRs}$ was annealed at $450{ }^{\circ} \mathrm{C}$ for duration of 3-4 h to get the complete conversion of nickel hydroxide into $\mathrm{NiO}$ crystalline phase. Both pure $\mathrm{NiO}$ and $\mathrm{ZnO}$ samples were also grown on FTO coated glass for comparison. The morphology and the structural properties of the nanofabricated heterostructures were studied by field emission scanning electron microscopy (FESEM) equipped with energy-dispersed X-ray spectroscopy (EDS) detector and by high-resolution transmission electron microscopy (HRTEM), respectively. HRTEM was carried out using an FEI Tecnai G2 TF20 UT (FEI, Eindhoven, The Netherlands) with a field emission gun working at $200 \mathrm{kV}$ and a point resolution of $1.9 \AA$. Crystal qualities of $\mathrm{NiO} / \mathrm{ZnO}$ nanorods was studied by X-ray diffraction (XRD, Oxford, United Kingdom) technique using a standard diffractometer. Cathodoluminescence (CL) technique was used for the investigation of luminescence properties of the proposed heterostructures based on p-type $\mathrm{NiO} / \mathrm{ZnO}$ nanostructures. CL spectra were measured using a Mono CL 4 system integrated with a LEO 1550 Gemini SEM (Zeiss, Oberkochen, Germany) and equipped with a fast CCD detection system and with a Peltier cooled photomultiplier tube for signal acquisition at an accelerating voltage of $10 \mathrm{kV}$. For low temperature CL measurement, a liquid-He-cooled stage has been used.

\section{Conclusions}

Closely-spaced and well-aligned coral reef-like composite nanostructures of p-type $\mathrm{NiO}$ on n-type ZnO NRs were fabricated on FTO glass substrate by the relatively cheap and simple hydrothermal growth method. CL study has shown an enhancement of the luminescence in the visible region and the effect is more pronounced at low temperatures. Moreover, the quantitative analysis of the cross-sectional study confirmed the enhancement in the visible emission of grown composite nanostructures as much as eight times more than pure $\mathrm{ZnO}$. The quantitative analysis and the obtained results indicate that the p-type $\mathrm{NiO} / \mathrm{n}$-type $\mathrm{ZnO}$ composite nanostructure is a promising material for the development of optoelectronic nanodevices.

\section{Acknowledgments}

This work was supported by the Swedish Energy Agency, the Swedish Research Council (VR), the Knut and Alice Wallenberg Foundation, and the Swedish Governmental Agency for Innovation Systems (VINNOVA).

\section{Conflicts of Interest}

The authors declare no conflict of interest. 


\section{References}

1. Look, D.C. Recent advances in ZnO materials and devices. Mat. Sci. Eng. B 2001, 80, 383-387.

2. Wang, Z.L. ZnO nanowire and nanobelt platform for nanotechnology. Mater. Sci. Eng. R 2009, 64, 33-71.

3. Willander, M.; Ul-Hasan, K.; Nur, O.; Zainelabdin, A.; Zaman, S.; Amin, G. Recent progress on growth and device development of $\mathrm{ZnO}$ and $\mathrm{CuO}$ nanostructures and graphene nanosheets. J. Mater. Chem. 2012, 22, 2337-2350.

4. Zhong, Z.; Qian, F.; Wang, D.; Lieber, C.M. Synthesis of p-type gallium nitride nanowires for electronic and photonic nanodevices. Nano Lett. 2003, 3, 343-346.

5. Ul-Hasan, K.; Alvi, N.H.; Lu, J.; Nur, O.; Willander, M. Single nanowire-based UV photodetectors for fast switching. Nano Res. Lett. 2011, 6, doi:10.1186/1556-276X-6-348.

6. Lee, S-K.; Kim, T-H.; Lee, S-Y.; Choi, K-C.; Yang, P. High-brightness gallium nitride nanowire UV-blue light emitting diodes. Philos. Mag. 2007, 87, 2105-2115.

7. Zhang, X.M.; Lu, M.Y.; Zhang, Y.; Chen, L.J.; Wang, Z.L. Fabrication of a high-brightness blue-light-emitting diode using a $\mathrm{ZnO}$-nanowire array grown on $\mathrm{p}-\mathrm{GaN}$ thin film. Adv. Mater. 2009, 21, 2767-2770.

8. Hsieh, Y.P.; Chen, H.Y.; Lin, M.Z.; Shiu, S.C.; Hofmann, M.; Chern, M.Y.; Jia, X.; Yang, Y.J.; Chang, H.J.; Huang, H.M.; et al. Electroluminescence from $\mathrm{ZnO} /$ Si-nanotips light-emitting diodes. Nano Lett. 2009, 9, 1839-1843.

9. Abbasi, M.A.; Ibupoto, Z.H.; Hussain, M.; Nur, O.; Willander, M. The fabrication of white light-emitting diode using the $\mathrm{n}-\mathrm{ZnO} / \mathrm{NiO} / \mathrm{p}-\mathrm{GaN}$ heterojunction with enhanced luminescence. Nano Res. Lett. 2013, 8, doi:10.1186/1556-276X-8-320.

10. Greene, L.E.; Law, M.; Tan, D.H.; Montano, M.; Goldberger, J.; Somorjai, G.; Yang, P. General route to vertical $\mathrm{ZnO}$ nanowire arrays using textured $\mathrm{ZnO}$ seeds. Nano Lett. 2005, 5, 1231-1236.

11. Li, D.; Leung, Y.H.; Djurišić, A.B.; Liu, Z.T.; Xie, M.H.; Shi, S.L.; Xu, S.J.; Chan, W.K. Different origins of visible luminescence in $\mathrm{ZnO}$ nanostructures fabricated by the chemical and evaporation methods. Appl. Phys. Lett. 2004, 85, 1601-1603.

12. Lupan, O.; Pauporte, T.; Viana, B. Low voltage UV-Electroluminescence from ZnO-nanowire array/p-GaN light-emitting diodes. Adv. Mater. 2010, 22, 3298-3302.

13. Alvi, N.H.; Riaz, M.; Tzamalis, G.; Nur, O.; Willamder, M. Fabrication and characterization of high brightness light emitting diodes based on $\mathrm{n}-\mathrm{ZnO}$ nanorods grown by low temperature chemical method on p-4H-SiC and P-GaN. Semicond. Sci. Technol. 2010, 25, doi:10.1088/02681242/25/6/065004.

14. Srinivasan, V.; Weinder, J.W. An electrochemical route for making porous nickel oxide electrochemical capacitors. J. Electrochem. Soc. 1997, 144, L210-L213.

15. Liu, K.C.; Anderson, M.A. Porous nickel oxide/nickel films for electrochemical capacitors. J. Electrochem. Soc. 1996, 143, 124-130.

16. Nam, K.W.; Kim, K.B. Synthesis of Li-doped nickel oxide thin film electrodes for electrochemical capactiors using electrostatic spray deposition technique. Electrochemistry 2001, 69, 467-472. 
17. Chrissanthopoulos, A.; Baskoutas, S.; Bouropoulos, N.; Dracopoulos, V.; Poulopoulos, P.; Yannopoulos, S.N. Synthesis and characterization of $\mathrm{ZnO} / \mathrm{NiO} \mathrm{p}-\mathrm{n}$ heterojunctions: $\mathrm{ZnO}$ nanorods grown on $\mathrm{NiO}$ thin film by thermal evaporation. Photon. Nanostruct. Fundam. Appl. 2001, 9, 132-139.

18. Khan, Y.; Hussain, S.; Söderlind, F.; Käll, P.-O.; Abbasi, M.A.; Durrani, S.K. Honeycomb $\beta-\mathrm{Ni}(\mathrm{OH})_{2}$ films grown on 3D nickel foam substrate at low temperature. Mater. Lett. 2012, 69, 37-40.

19. Abbasi, M.A.; Ibupoto, Z.H.; Hussain, M.; Khan, Y.; Khan, A.; Nur, O.; Willander, M. Potentiometric zinc ion sensor based on honeycomb-like NiO nanostructures. Sensors 2012, 12, 15424-15437.

20. Chang, S.-P.; Lu, C.-Y.; Chang, S.-J.; Chiou, Y.-Z.; Hsu, C.-L.; Su, P.-Y.; Hsueh, T.-J. A novel fabrication of $\mathrm{p}$-n diode based on $\mathrm{ZnO}$ nanowire/p-NiO heterojunction. Jpn. J. Appl. Phys. 2011, 50, doi:10.1143/JJAP.50.01AJ05.

21. Yang, Z.-G.; Zhu, L.-P.; Guo, Y.-M.; Tian, W.; Ye, Z.-Z.; Zhao, B.-H. Valance-band offset of $\mathrm{p}-\mathrm{NiO} / \mathrm{n}-\mathrm{ZnO}$ heterojunction measured by X-ray photoelectron spectroscopy. Phys. Lett. A 2011, 375, 1760-1763.

22. Ohta, H.; Hirano, M.; Nakahara, K.; Maruta, H.; Tanabe, T.; Kamiya, M.; Kamiya, T.; Hosono, H. Fabrication and photo response of a pn-heterojunction diode composed of transparent oxide semiconductors, p-NiO and n-ZnO. Appl. Phys. Lett. 2003, 83, 1029-1031.

23. Abbasi, M.A.; Ibupoto, Z.H.; Khan, A.; Nur, O.; Willander, M. Fabrication of UV photo-detector based on coral reef like p-NiO/n-ZnO nanocomposite structures. Mater. Lett. 2013, 108, 149-152.

24. Wang, J.-Y.; Lee, C.-Y.; Chen, Y.-T.; Chen, C.-T.; Chen, Y.-L.; Lin, C.-F.; Chen, Y.-F. Double side electroluminescence from $\mathrm{p}-\mathrm{NiO} / \mathrm{n}-\mathrm{ZnO}$ nanowire heterojunctions. Appl. Phys. Lett. 2009, 95, doi:10.1063/1.3232244.

25. Long, H.; Fang, G.; Huang, H.; Mo, X.; Xia, W.; Dong, B.; Meng, X.; Zhao, X. Ultraviolet electroluminescence from $\mathrm{ZnO} / \mathrm{NiO}$-based heterojunction light-emitting diodes. Appl. Phys. Lett. 2009, 95, doi:10.1063/1.3176440.

26. Fu, Z.; Dong, W.; Yang, B.; Wang, Z.; Yang, Y.; Yan, H.; Zhang, S.; Zuo, J.; Ma, M.; Liu, X. Effect of $\mathrm{MgO}$ on the enhancement of ultraviolet photoluminescence in $\mathrm{ZnO}$. Solid State Comm. 2006, 138, 179-183.

27. Shimpi, P.; Gao, P.X.; Goberman, D.G.; Ding, Y. Low temperature synthesis and characterization of $\mathrm{MgO} / \mathrm{ZnO}$ composite nanowire arrays. Nanotechnology 2009, 20, doi:10.1088/0957-4484/ 20/12/125608.

28. Richter, J.P.; Voss, T.; Kim, D.S.; Scholz, R.; Zacharias, M. Enhanced surface-excitonic emission in $\mathrm{ZnO} / \mathrm{Al}_{2} \mathrm{O}_{3}$ core-shell nanowires. Nanotechnology 2008, 19, doi:10.1088/0957-4484/ 19/30/305202.

29. Yu, D.W.; Li, X.M.; Gao, X.D. Microstructure and photoluminescence properties of bulk-quantity $\mathrm{SnO} 2$ nanowires coated with $\mathrm{ZnO}$ nanocrystals. Nanotechnology 2005, 16, doi:10.1088/0957-4484/ $16 / 12 / 004$.

30. Shi, L.; Xu, Y.; Hark, S.; Liu, Y.; Wang, S.; Peng, L.; Wong, K.; Li, Q. Optical and electrical performance of $\mathrm{SnO}_{2}$ capped $\mathrm{ZnO}$ nanowire arrays. Nano Lett. 2007, 7, 3559-3563. 
31. Li, X.; Zhang, Y.; Ren, X. Effects of localized surface plasmons on the photoluminescence properties of Au-coated $\mathrm{ZnO}$ films. Optics Express 2009, 17, 8735-8740.

32. Abiyasa, A.P.; Yu, S.F.; Lau, S.P.; Leong, E.S.P.; Yang, H.Y. Enhancement of ultraviolet lasing from Ag-coated highly disordered $\mathrm{ZnO}$ films by surface-plasmon resonance. Appl. Phys. Lett. 2007, 90, 231106.

33. Lin, J.M.; Lin, H.Y.; Cheng, C.L.; Chen, Y.F. Giant enhancement of bandgap emission of ZnO nanorods by platinum nanoparticles. Nanotechnology 2006, 17, doi:10.1088/0957-4484/17/17/017.

34. Zou, C.W.; Jan, X.D.; Han, J.; Chen, R.Q.; Bian, J.M.; Haemmerle, E.; Gao, W. Preparation and enhanced photoluminescence property of ordered $\mathrm{ZnO} / \mathrm{TiO}_{2}$ bottlebursh nanostructures. Chem. Phys. Let. 2009, 476, 84-88.

35. Breedon, M.; Yu, J.; Wlodarski, W.; Kalanter-zadeh, K. ZnO Nanostructured Arrays Grwon from Aqueous Solution on Different Substrates. In Proceeding of Nanoscience and Nanotechnology, Melbourne, Australia, 25-29 February 2008.

36. Mochizuki, S.; Saito, T. Intrinsic and defect related luminescence of NiO. Phys. B 2009, 404, 4850-4853.

37. Subramanian, B.; Ibrahim, M.M.; Kumar, V.S.; Murali, K.R.; Vidhya, V.S.; Sanjeeviraja, C.; Jayachandran, M. Optoelectronic and electrochemical properties of nickel oxide (NiO) films deposited by DC reactive magnetron sputtering. Phys. B 2008, 403, 4104-4110.

38. Khan, Y.; Hussain, S.T.; Abbasi, M.A.; Kall, P.-O.; Soderlind, F. On the decoration of 3D nickel foam with single crystal $\mathrm{ZnO}$ nanorod arrays and their cathodoluminescence study. Mater. Lett. 2013, 90, 126-130.

39. Abbasi, M.A.; Khan, Y.; Hussain, S.; Nur, O.; Willander, M. Anions effect on the low temperature growth of $\mathrm{ZnO}$ nanostructures. Vacuum 2012, 86, 1998-2001.

40. Djurisic, A.B.; Leung, Y.H.; Tam, K.H.; Ding, L.; Ge, W.K.; Chen, HY.; Gwo, S. Green, yellow, and orange defect emission from $\mathrm{ZnO}$ nanostructures: Influence of excitation wavelength. Appl. Phys. Lett. 2006, 88, doi:10.1063/1.2182096.

41. Cao, B.; Cai, W.; Zeng, H. Temperature-dependent shifts of three emission bands for $\mathrm{ZnO}$ nanoneedle arrays. Appl. Phys. Lett. 2006, 88, doi:10.1063/1.2195694.

42. Dijken, A.V.; Meulenkamp, E.A.; Vanmaekelbergh, D.; Meijerink, A. The kinetics of the radiative and nonradiative process in Nanocrystalline $\mathrm{ZnO}$ particles upon photo excitation. $J$ Phys. Chem. B 2000, 104, 1715-1723.

43. Wang, Y.; Niu, Q.; Hu, C.; Wang, W.; He, M.; Zhang, Y.; Li, S.; Zhao, L.; Wang, X.; $\mathrm{Xu}, \mathrm{J} . ;$ et al. Ultrathin nickel oxide film as a hole buffer layer to enhance the optoelectronic performance of a polymer light-emitting diode. Optics Lett. 2011, 36, 1521-1523.

(C) 2014 by the authors; licensee MDPI, Basel, Switzerland. This article is an open access article distributed under the terms and conditions of the Creative Commons Attribution license (http://creativecommons.org/licenses/by/3.0/). 